\title{
DOS CARTAS INÉDITAS DE LAGASCA A HUMBOLDT EN TORNO AL LEGADO DE MUTIS
}

\author{
Miguel Ángel Puig-Samper, J. Luis Maldonado \\ Instituto de Historia, CSIC, Madrid \\ Xosé Fraga
}

I.E.S. Monelos, A Coruña

\section{RESUMEN}

Antes de la partida hacia América, Alejandro de Humboldt se documentó sobre la historia natural americana y las expediciones científicas españolas. En el presente artículo, damos a conocer dos importantes cartas de Mariano Lagasca, que desde su exilio londinense, escribió a Humboldt en torno al legado científico de José Celestino Mutis y su llegada a España tras la intervención militar del general Morillo en Nueva Granada.

PALABRAS CLAVE: Humboldt, Lagasca, Mutis, Londres, Nueva Granada.

\section{SUMMARY}

Before departing for America, Alejandro de Humboldt documented American natural history and the Spanish scientific expeditions. This article reveals two important letters of Mariano Lagasca who, from exile in London, wrote to Humboldt about the scientific legacy of José Celestino Mutis, and his arrival in Spain following the military intervention of general Morillo in Nueva Granada.

KEY WORDS: Humboldt, Lagasca, Mutis, London, Nueva Granada.

\section{HUMBOLDT Y LOS CIENTÍFICOS ESPAÑOLES}

Tradicionalmente, sobre todo desde la historiografía humboldtiana española, se ha discutido bastante la posible o trascendente influencia de la ciencia española sobre la obra de Humboldt en América, haciendo hincapié especialmente en lo que el sabio prusiano pudo absorber de los conocimientos de las diversas expediciones científicas que recorrían el territorio americano en el 
momento de su gran viaje ${ }^{1}$. Antes de su partida hacia América, Alejandro de Humboldt se documentó de forma precisa de lo que en ese momento se sabía en la Corte sobre la historia natural americana, sin que ello implicase una copia mecánica en su obra posterior. En el campo de la ciencia, Humboldt pudo llegar de la mano del barón de Forell al Real Gabinete de Historia Natural, institución científica con la que el embajador de Sajonia colaboraba con sus colecciones mineralógicas y en la que incluso había logrado colocar como colectores a dos alemanes, Juan Guillermo y Enrique Talacker. Además parecía evidente el aprecio por la mineralogía alemana del vicedirector y director efectivo del Real Gabinete de Historia Natural, José Clavijo y Fajardo, si tenemos en cuenta que hacía poco tiempo había enviado una expedición mineralógica a Chile y Perú dirigida por los hermanos Heuland, sobrinos del gran coleccionista Jacob Forster ${ }^{2}$, y había promovido a catedrático de mineralogía en Madrid a Cristiano Herrgen.

Paralelamente, Humboldt establecería relaciones científicas con los químicos Louis Proust y Domingo García Fernández, quienes con el botánico Cavanilles y Herrgen estaban a punto de publicar la primera revista científica española, los Anales de Historia Natural ${ }^{3}$. Para completar sus conocimientos, Casimiro Gómez Ortega, por entonces director del Real Jardín Botánico, le permitió conocer el contenido de las floras americanas elaboradas en las expediciones científicas que los gobiernos ilustrados habían enviado a América, especialmente las dirigidas a Perú y Nueva España. También llegó a conocer a Juan Bautista Muñoz, el ilustre historiador que en esos años organizaba el Archivo General de Indias y preparaba su Historia del Nuevo Mundo, a José Chaix, un astrónomo

1 Especialmente Álvarez, E. (1960), «Alejandro de Humboldt y los naturalistas españoles», Conferencias leídas en la Academia en los días 19 y 22 de octubre de 1959, con motivo del centenario del fallecimiento de Alejandro de Humboldt. Madrid: Real Academia de Ciencias Exactas, Físicas y Naturales, 129-166 y (1964), «El viaje a América de Alexander von Humboldt y Aimé Bonpland y las relaciones científicas de ambos expedicionarios con los naturalistas españoles de su tiempo», Anales del Instituto Botánico A.J. Cavanilles, XXII, 11-60; MANJARRÉS, R. (1915), Alejandro de Humboldt y los españoles, Sevilla, Establecimiento Tipográfico de la Guía Oficial; Melón, A. (1933), Alejandro de Humboldt en la América española. Discurso leido en la solemne apertura del curso académico 1932 a 1933, Universidad de Valladolid, Tip. Cuesta y (1957), «Humboldt en el conocer de la España peninsular y canaria», Estudios Geográficos, 67-68, 239-259.

2 Véase ARIAS, J. C. (1978), Expedición Científica de los hermanos Heuland, Madrid, Ediciones Cultura Hispánica.

3 FERnÁNDEZ, J. (Ed.) (1993), Anales de historia natural 1799-1804, 3 tomos, Aranjuez, Comisión Interministerial de Ciencia y Tecnología. 
distinguido que había trabajado con Delambre y Méchain en las operaciones de medición del arco de meridiano en España y que fue uno de los principales colaboradores de Humboldt, así como al grupo de marinos ilustrados que en su mayor parte estaban relacionados con el Depósito Hidrográfico de Madrid. En este centro se elaboraba la principal cartografía naútica de la época, que dirigía el marino José Espinosa y Tello, más tarde sustituido por Felipe Bauzá, otro de los corresponsales más activos de Alejandro de Humboldt ${ }^{4}$.

Además de los científicos españoles ya citados, habría otros dos grupos que tendrían una relación privilegiada con el sabio de Tegel, los exiliados en Londres —entre los que se encontraban personajes como Lagasca o Bauzá- y aquellos con los que contactó en su periplo americano, como José Celestino Mutis, Francisco José de Caldas, Vicente Cervantes, Tafalla, etc. Son precisamente dos componentes de estos grupos los que nos ocupan en el presente artículo, en que damos a conocer dos importantes cartas de Mariano Lagasca a Alejandro de Humboldt en torno al legado de Mutis, herencia científica enviada a España tras la intervención militar en Nueva Granada del general Morillo. Antes de abordar el comentario estricto de estos documentos, haremos una leve revisión de la relación de Alejandro de Humboldt con Mutis y Lagasca.

\section{MuTiS Y HUMBOLDT}

El empeño de Humboldt en conocer a José Celestino Mutis en Santa Fé de Bogotá $^{5}$, en una de las etapas de su viaje americano, tiene una explicación sencilla. Cuando, después de contrastar sus mediciones astronómicas con Fidalgo y conocer a Pombo en Cartagena, éste le sugiere el recorrido más difícil para llegar a Guayaquil siguiendo el curso del río Magdalena; el sabio prusiano no lo duda. Aprovecha para levantar la cartografía de Nueva Granada y acercarse al amigo de Linneo, supuestamente el mejor conocedor de la flora americana y un experto que puede asesorarle en sus dudas taxonómicas, el aspecto que menos le interesa pero al que sin duda sabe que tiene que atender para satisfacer al mundo científico europeo y para el que cuenta con la

4 Puig-Samper, M. A. (1999), «Humboldt. un prusiano en la corte del rey Carlos IV», Revista de Indias LIX (216), 329-355.

5 Sobre Mutis, véase la aportación de FríAs, M. (1994), Tras el Dorado Vegetal. José Celestino Mutis y la Real Expedición Botánica del Nuevo Reino de Granada, Sevilla, Diputación de Sevilla y SAN Pío, M.P. (Ed.) (1992), Mutis y la Real Expedición Botánica del Nuevo Reyno de Granada, Bogotá-Madrid, Venegas-Lunwerg. 
eficaz colaboración de Bonpland. José Ignacio de Pombo al anunciar desde Cartagena a Mutis, el 20 de abril de 1801, el viaje de Humboldt, quien viajaba acompañado de Bonpland y del médico francés Louis Rieux, le recomendó vivamente, por el apoyo de la corte española, por su fama y por sus observaciones y descubrimientos en torno al galvanismo. Además, Pombo indicaba cómo Humboldt le había comentado su interés en conocer personalmente a Mutis, mucho más consagrado en el extranjero que en la propia España ${ }^{6}$.

Nueve días más tarde, José Celestino Mutis escribía a Humboldt desde Santafé para agradecerle su visita:

«...tan apreciable me ha sido la resolución de continuar Vm. su viaje a Quito viniendo por Santafé con el único objeto de reconocer la Flora de Bogotá, y proporcionar a su autor los agradables momentos de su generosa amistad, que reputaré por los más felices de mi vida los días de su residencia en esta Capital del Reyno» ${ }^{7}$.

El propio Humboldt, en una de las primeras descripciones de su viaje dedicada al público norteamericano, señalaba el interés de su encuentro con el sabio gaditano tras pasar por Cartagena:

«La temporada estaba demasiado avanzada para la navegación en el mar del Sur, había que abandonar el proyecto de cruzar el Istmo y el deseo de ver de cerca al célebre Mutis y de admirar sus inmensas riquezas de historia natural, hizo que Humboldt se quedara unas semanas en los bosques de Turbaco y subiera en 40 días el bello río Magdalena, del que esbozó un mapa. Desde Honda nuestros viajeros subieron por los bosques de robles, de Melastoma y de Chinchona (Peruvian-bark) hasta Santa Fe de Bogotá, la capital del Reino de Nueva Granada situada en una bella planicie elevada 1360 toesas por encima del nivel del mar. Las extraordinarias colecciones de Mutis, la grande y majestuosa catarata de Tequendama, con una caída de 98 toesas de altura, las minas de Mariquita, de Santa Ana y de Zipaquirá, el puente natural de Icononzo (tres piedras dispuestas en forma de arco por un terremoto), estas son las curiosidades que detuvieron a Humboldt y Bonpland hasta el mes de septiembre de 1801» ${ }^{8}$.

Quizá del contacto con Mutis pudo obtener una cierta visión iconográfica de la flora americana, muy útil en la descripción de las floras tropicales, que

6 Archivo del Real Jardín Botánico de Madrid (RJB), III, 1, 1, 244.

7 RJB, III, 1, 2, 34.

8 Humboldt, A. (1804), Relato sobre su viaje en América del Sur y Mesoamérica (Newcastle, finales de junio 1804), Filadelfia, American Philosophical Society Library, Misc. Ms. Coll. (V). La traducción inglesa apareció en The Literary Magazine and American register for 1804, tomo 2, 321-327. 
se resistían a ser clasificadas por el estricto sistema linneano y - como el mismo Humboldt verá más tarde- encajaban mejor en los sistemas naturales de clasificación, que en esos momentos intentaba desarrollar su amigo Jussieu. Tanto él como Bonpland reconocerán frecuentemente la deuda contraída con Mutis por su ayuda en la resolución de sus dudas botánicas y, ya en Ecuador, lamentarán no disponer de su valioso asesoramiento9. El mismo Alejandro de Humboldt comentará muchos años más tarde —en la biografía que le dedicó en el diccionario biográfico de Michaud - la gran impresión producida por la colección de dos mil láminas que había podido reconocer en su encuentro con el naturalista español, de las que destacaba cuarenta y tres de pasifloras y ciento veinte de orquídeas, además de la colección botánica elaborada con sus discípulos Valenzuela, Zea y Caldas ${ }^{10}$.

La propia representación de la Naturaleza en la obra de Humboldt dará un salto respecto a la más estricta visión ilustrada, ya que sin despreciar los icones típicos de las descripciones linneanas que representaban la singularidad de una especie, que Humboldt y Bonpland utilizarán en sus obras taxonómicas, los cuadros humboldtianos buscan la representación global y sintética de las regiones naturales y un nuevo sentido estético de ambiente romántico que aunase la fría racionalidad ilustrada con el sentimiento subjetivo del científico ante la contemplación de la Naturaleza.

\section{LAGASCA Y HUMBOLDT}

Mariano Lagasca, aunque prematuramente arrebatado para la ciencia española, fue un botánico de primer orden en la línea de los más importantes naturalistas e intelectuales del momento, que reconocieron y valoraron su categoría científica. Su relación con Alejandro de Humboldt, mantenida e intensificada a lo largo del tiempo mediante la correspondencia epistolar, se remontaba, sin embargo, a los años en que el viajero prusiano visitó nuestro país camino de su periplo americano y donde éste conoció a los mejores científicos españoles de la época, entre los que destacó su relación con Felipe Bauzá.

9 El estudio del contacto entre Mutis y Humboldt puede hacerse muy bien a través de los manuscritos conservados en el Real Jardín Botánico y clasificados perfectamente en (1995), Catálogo del Fondo Documental José Celestino Mutis del Real Jardín Botánico, Madrid, Instituto Colombiano de Cultura Hispánica-Real Jardín Botánico.

10 (1843), Biographie Universelle ancienne et moderne. Publiée sous la direction de Michaud, M., Paris, A. Thoisnier Desplaces Éditeur, 658-662. 


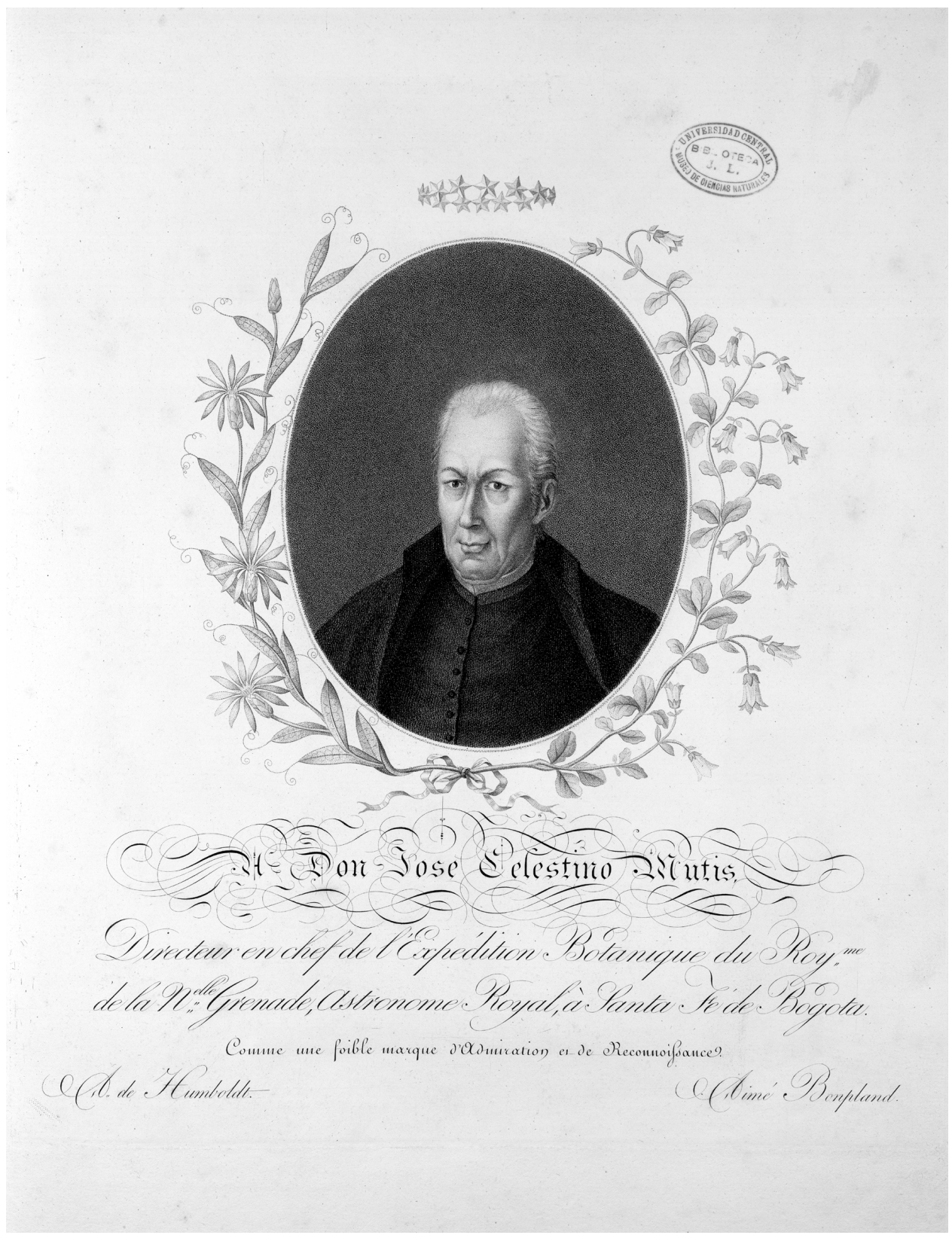

Retrato de Mutis (Real Jardín Botánico, CSIC) 
En el caso que nos ocupa, uno de los mejores discípulos de Lagasca, Eduardo Carreño, en la necrológica que escribió sobre su maestro, afirma que Humboldt conoció a Lagasca en 1799 en la región levantina en el último de los años en que éste estudiaba medicina en Valencia y comenta al respecto: «quedó sorprendido ante su tacto en la determinación de las plantas y su habilidad en el conocimiento de las especies» ${ }^{11}$

En este punto haremos un breve paréntesis para mostrar un perfil biográfico de Lagasca (Encinacorba, Zaragoza,1776-Barcelona, 1839) ${ }^{12}$. Tras sus primeros estudios de latín, filosofía, teología y humanidades, el joven Lagasca se inclinó por los estudios de medicina, que comenzó primero en la Universidad de Zaragoza y luego en la de Valencia, para finalizarlos en 1801 en el Real Estudio de Madrid. Sin embargo su inclinación por las ciencias naturales y en especial por la botánica se debió a la influencia de Antonio Verdejo y Antonio Martí Franqués y sirvió para que esta fuera su principal dedicación a lo largo de su vida, que en gran parte estuvo ligada a la historia del Real Jardín Botánico de Madrid (RJB). En esta institución, además de conocer a Casimiro Gómez Ortega, estableció una intensa amistad con el que iba a ser su gran compañero científico Simón de Rojas Clemente.

La relación con Antonio José Cavanilles sería la más fructífera para el científico aragonés. Colaboró en las Variedades de ciencias, literatura y artes $\mathrm{y}$, con el director del RJB, en los Anales de Ciencias Naturales, quien asimismo le encargó recolectar plantas en el norte peninsular y aportar los datos fitogeográficos necesarios para la Flora Española iniciada por Miguel Barnades. De esta experiencia de campo merece especial atención su descubrimiento en las montañas astur-leonesas, en julio de 1803, del interesante liquen islándico (Cetraria islandica), preciado vegetal muy útil para remediar las enfermedades de tipo pulmonar.

En 1803, Cavanilles le propuso como segundo profesor o viceprofesor del RJB, cargo que obtuvo del gobierno en 1806 y en 1807 el de profesor de Botánica Médica, empleando en sus clases por primera vez el método de fami-

11 Según comenta: REYES, E. (1917), Estudio bio-bibliográfico de M. La Gasca y Segura, Madrid, pp.220-221.

12 Álvarez, E. (1969), «Notas sobre botánicos aragoneses. Con motivo de un homenaje». Anales del Instituto Botánico A.J. Cavanilles, t. XVIII, Madrid, pp. 9-13; CARreÑO, E. (1840), «Notice sur la vie et les escrits du botaniste espagnol Dr. Mariano La Gasca», Annales des Sciences Natureles, París, 1-16; ReYes, E. (1917); RocAmORA, M. (1955), Estancia y fallecimiento del botánico La Gasca en Barcelona (1834-1839), Barcelona. Todos los datos proceden de estos autores, pero especialmente de: YÁÑEZ, A. (1842), Elogio histórico de Mariano Lagasca y Segura. Barcelona. 
lias naturales. Con la imposición de José I como rey de España y la ocupación de Madrid a finales de 1808 por las tropas francesas, se procuró atraer a Lagasca a las filas afrancesadas. Por mediación de Humboldt, José Bonaparte, le propuso como director del RJB, pero su posición política le impidió cumplir con el encargo. Se incorporó en 1809 a la resistencia contra los franceses durante los seis años que duró la contienda como médico de número del tercer ejército en las provincias del sur. Aparte de su labor sanitaria y hospitalaria, combatió la temible epidemia de fiebre amarilla en Murcia, publicó en Orihuela el primer número de las Amenidades naturales de las Españas, muy conocido en la historia de la botánica por la monografia Disertación sobre un nuevo orden de plantas de la clase de las compuestas, que marcó su inicio epistolar con Bonpland al hablarle de esta familia botánica ${ }^{13}$. En 1821 publicó en Madrid, en el segundo número, la monografía sobre la familia de las umbelíferas.

La Regencia del Reino en 1813 le concedió interinamente la primera cátedra y dirección del RJB, cargos que el rey le confirió en propiedad poco después, dedicándose a su restablecimiento y a superar las limitaciones y recortes de competencias al crearse la Junta de Protección del Museo de Ciencias Naturales, dependiente del gobierno. Además de catedrático de botánica general, continuó con sus dos obras botánicas prioritarias: la Flora Española y la $\mathrm{Ce}$ res, esta última en colaboración con su amigo Clemente. En 1816 publicó su Elenchus plantarum H.R.M., catálogo de las plantas del RJB y al año siguiente la Memoria de las plantas barrilleras de España, nombrándosele Inspector General de los Plantíos y Arbolados del Canal del Manzanares.

Colaboró en la edición que hizo la Sociedad Económica Matritense de la obra de agricultura de Herrera y durante el Trienio Liberal participó en política como diputado a Cortes por Aragón ${ }^{14}$, lo que como liberal declarado, con la restauración absolutista le llevó al exilio como a muchos de sus colegas parlamentarios, entre los que se encontraba también Felipe Bauzá, el otro amigo de Humboldt. Después de su paso por Sevilla, Cádiz y Gibraltar llegó a Londres en 1824 donde continuó con sus estudios botánicos, gracias a las

13 CASASECA, B. (1976), «La vida de La Gasca» Lagascalia, 6(2), 191-201. Lagasca, en carta que escribió a Bonpland, establecía, como Decandolle, la familia particular de las Compuestas, entre las Achicoráceas y las Cinarocéfalaceas, incluyendo géneros que complementaban la historia de esa familia, que el eminente botánico suizo formuló contando con su información.

14 Maldonado, J.L. (2003), "Científicos americanos en las Cortes Constituyentes. La cuestión ultramarina», Revista de Indias, LXIII, $\mathrm{n}^{\circ}$ 227, 275-302, Madrid y «Ciencia y política. Los botánicos Mariano Lagasca y Simón de Rojas Clemente en las cortes del Trienio Liberal», Hispania, LXIII/3, n²15, 103-156, Madrid. 
ayudas que le prestaron los mejores botánicos ingleses del momento ${ }^{15}$. Examinó el herbario de Linneo, recorrió los jardines y museos londinenses; la Sociedad de farmacéuticos de Londres puso a su disposición el jardín de Chelsea para que cultivase las gramíneas y umbelíferas, se ocupó también de clasificar el herbario de un botánico inglés procedente de un viaje a la India, lo que le reportó el dinero suficiente para poder trasladar a su familia que aún permanecía en Cádiz. Publicó artículos en el Gardener's Magazine y sus $O b$ servaciones sobre la familia de las aparasoladas aparecieron en el periódico editado por el grupo de españoles expatriados Ocios de los españoles emigrados; colaboró asimismo en el Semanario de Agricultura y Artes que publicaba uno de esos exilados, Marcelino Calero.

En Inglaterra reanudó sus trabajos sobre la Ceres, tras la muerte de Clemente en 1827, cuya redacción se prolongaría hasta el final de sus días ${ }^{16}$. De algunas excursiones por los alrededores de Londres, Lagasca colectó algunas plantas que le sirvieron para publicar las cuatro entregas que formaron un tomo del Hortus Siccus Londinensi ${ }^{17}$. Escribió nuevos tratados sobre las familias de las gramíneas y aparasoladas; tradujo y aumentó con notas curiosas la Teoría elemental de Botánica de Decandolle, que quedó inédita en poder de su familia, y volvió a componer e incorporar las novedades científicas producidas de los Elementos de Botánica del mismo Decandolle, que había perdido en Sevilla durante su precipitada huida de España.

La mala salud de Lagasca, seguramente tuberculosis, le obligó a salir de Londres en 1831 en busca de un clima más benigno. Residiendo en Saint Heliers, en la isla de Jersey, colaboró con el agrónomo inglés John Le Couteur en cuestiones agrícolas, pero por un decreto de la reina gobernadora, de 23 de octubre de 1833, Lagasca y algunos otros compañeros de exilio son amnistiados y se les repone en los puestos que ocupaban antes de 1823. En 1837 , pese a las intrigas y enemistades de algunos de sus colegas, ocupó la presidencia de la recién creada Junta de Profesores encargada de la Dirección y Administración del Museo de Ciencias Naturales, se incorporó a la enseñanza en el RJB, el gobierno le condecoró con la cruz de Comendador de la

15 LlORENS, V. (1968), Liberales y Románticos. Una emigración española en Inglaterra, 1823-1834, Madrid, Castalia, $2^{\mathrm{a}}$ ed., p.45.

16 Tellez, R. y Alonso, M. (1952), Los trigos de la Ceres Hispánica de Lagasca y Clemente, Madrid, INIA.

17 Un estudio pormenorizado de este trabajo pude verse en: MALDONADO, J.L. «La botánica del exilio. Mariano Lagasca y el «Hortus Siccus Londinensis», Anales del Jardín Botánico, Madrid (en prensa). 
orden de Isabel la Católica y numerosas sociedades científicas europeas le distinguieron con otros emblemas honoríficos. El 21 de diciembre de 1838, buscando un clima más favorable tras el agravamiento de su estado de salud, llegó a Barcelona donde falleció de una angina de pecho el 26 de junio de 1839 a los 62 años.

\section{LAGASCA Y EL LEGADO DE MUTIS}

El período comprendido entre 1814 y 1817 fue el más importante en la obra de Lagasca. Desde que se hizo cargo del RJB tejió una extensa red de corresponsales por toda la península entre los que se encontraban algunos de los mas distinguidos botánicos españoles como: Martí Franqués, Francisco Bahí, Ignacio Graells, Francisco Bolós, Antonio Cabrera y otros de menor entidad. Algunos de éstos colaboraron con Lagasca en una de las actividades que éste acometió en esos años, como fue el intento de publicación de los trabajos de José Celestino Mutis, tras su rescate y conservación en Madrid en octubre de 1817. Su interés personal en tener el control sobre los materiales botánicos y el celo mostrado por esta comisión que encabezó nos lo demuestra a propósito de su valoración de uno de los manuscritos mutisianos, «la quinología o tratado de las quinas de Santa Fe de Bogotá»». A su juicio ésta no podía ordenarse y perfeccionarse sino por un médico y botánico como él, de manera que se dirigió al rey solicitando su nombramiento como encargado de su publicación e impresión en la Real Imprenta ${ }^{18}$. Además, uno de sus corresponsales en Córdoba, el clérigo José Jesús Muñoz, en los primeros meses de 1815 sentía la falta de recursos y de ayudantes que precisaba Lagasca para ese proyecto editorial. Muñoz había leído parte de la correspondencia del sabio gaditano que conservaba en la ciudad cordobesa un canónigo amigo suyo, Diego Ugalde, - de quien la heredó a su muerte y puso a su disposición para lo que pudiera resultar de utilidad - y se lamentaba de que aún no hubiesen visto la luz «tales tesoros que le ha costado tantos afanes a los sabios y tantas cantidades al erario». El colaborador estimulaba la iniciativa de Lagasca, más

18 Petición de Lagasca al rey. Madrid, 4 de octubre de 1817. RJB, I, 26,2,7. Como es sabido Mutis no publicó en vida ningún libro. Lagasca comenzó la tarea de editar los trabajos y obras científicas del gaditano y José Pavón, por Real Orden, fue encargado de continuarla. En el caso de la "Quinología», o mejor dicho El Arcano de la Quina, nombre con el que se conoce, se publicó finalmente, aumentada con notas y un Apéndice, en la imprenta de Ibarra de Madrid en 1828; edición que corrió a cargo del boticario de la Corte Manuel Hernández de Gregorio. 
aún desde que tuvo noticias de la llegada a Cádiz de los materiales de Mutis, pero transmitió a Lagasca su inquietud por la desidia de que se había hecho gala anteriormente con los trabajos de Hernández o los de Née, que «si se hubieran dado a la luz en su tiempo tantos trabajos de estos y de otros españoles quizá no se nos harían de nuevo muchas cosas [reproches] que se leen en Humboldt y otros extranjeros» ${ }^{19}$.

Abundando en estos aspectos, otro de los más asiduos colaboradores de Lagasca, el magistral de Cádiz Antonio Cabrera, se mostró muy interesado, como gaditano, por el destino de los materiales de su paisano, sobre todo después de la dudosa publicación de parte de éstos en la República de Cundinamarca - la Quinología, a la que se alude en una de las cartas de Lagasca a Humboldt transcritas en este artículo - y desde que se enteró de la remisión a la Corte desde Cádiz de «varios cajones de plantas del Reyno de tierra firme», lo que daba la posibilidad real de que los naturalistas europeos pudiesen ver «muchas cosas nuevas recogidas por el famoso Mutis», y que «el pensamiento frío de no hay dinero, obscurezca, o inutilice esos trabajos» ${ }^{20}$.

El que fuera virrey de Nueva Granada unos años antes de la llegada de Humboldt, José de Espeleta, aficionado a la botánica, se interesó por la obra de Mutis y su hijo, homónimo, colaboró con Lagasca en esta cuestión, al margen de su compromiso como correspondiente del RJB. Con el consentimiento de Pascual Enrile le remitió cuatro láminas de Mutis que tenía su padre de la colección que llegó a Madrid, para que hiciera los correspondientes duplicados de cara a mejorar su edición ${ }^{21}$. Por otro lado Lagasca informó a su colega y posterior amigo en su etapa londinense, Aymer Burke Lambert, sobre la marcha de los trabajos que se realizaban en el RJB con los materiales de las floras americanas y de su paralización editorial. Sobre la Flora de Santa Fe de Bogotá y demás materiales de la expedición de Nueva Granada le comunicó su contenido después de su llegada a Madrid (6769 dibujos, 85 cajones con esqueletos, maderas, resinas y otras drogas, pericarpos y semillas, además de los manuscritos de Mutis) y de la paralización de la publicación por el momento, pese a que el rey le encargó esa tarea ${ }^{22}$. De los 105 cajones de productos naturales que contenían el total de la remesa, procedente de

19 Cartas de José Jesús Muñoz a Lagasca. Córdoba, 6 de febrero de 1815, 17 de septiembre de 1816, 19 de junio de 1817 y 6 de noviembre de 1820 . RJB, I,56,6,23,25 y 27-29

20 Cartas de Antonio Cabrera a Lagasca. Cádiz, 16 de julio de 1816 y 12 de febrero de 1818. RJB, I,56,3,33 y 34

21 Carta de José de Espeleta a Lagasca. Pamplona, 9 de agosto de 1816. RJB, I,56,5,19.

22 Carta de Lagasca a Lambert. [Madrid, V-VI de 1819]. RJB, I,57,5,19. 
Nueva Granada que trajo a Madrid Pascual Enrile, los 85 con todo lo relativo al reino vegetal fueron reclamados por Lagasca, ante la disputa por su custodia entre el Ministerio de Estado y el de Gracia y Justicia de Indias, para depositarlos en el RJB y, del mismo contingente, lo referente a minerales y animales en el Real Gabinete de Historia Natural ${ }^{23}$.

Disponiendo de los materiales en el RJB y estando Lagasca como encargado de su inventariado, estudio y publicación, dispuso durante dos años de un presupuesto del «fondo de arbitrios piadosos» para costear los gastos ocasionados por la ordenación «colocación y conservación» de los fondos de la Flora de Santa Fé de Bogotá. La cantidad que se asignó, aunque insuficiente, sirvió para que Lagasca contara con la ayuda del pintor Diego García, para el que en octubre de 1819 se aprobaba una retribución complementaria de 3.205 reales del mismo fondo 24 .

Al parecer la polémica suscitada por los ministerios señalados se resolvió favorablemente según el deseo de Lagasca y al finalizar este último año, el ministro de Estado, por indicación de la Junta de Protección del Museo, le ordenaba que terminara definitivamente el traspaso de la remesa «arreglada a los inventarios que se acompañaron» de modo que el capitán Van Halen, responsable directo de su traslado a la Corte desde Nueva Granada, quedase libre del encargo para poder incorporarse al ejército del general Morillo ${ }^{25}$. Los materiales constatados, aunque en buen estado, no coincidían con los que Lagasca pudo ordenar e inventariar en presencia del mismo Van Halen, quien por encargo de los generales Enrile y Morillo se responsabilizó de la misión y que durante la travesía desde América, actuó con un enorme celo en su conducción.

$\mathrm{Y}$ en efecto, el requisito se verificó sin demora, si bien Lagasca advertía tanto al ministro como a la Junta, que dejaría «para el debido tiempo la execución del inventario systematico y circunstanciado», y les recordaba que en 1818 ya había remitido «el inventario de los dibujos, que se diferencia del original por no pocas e importantes circunstancias», entre otras por haber incluido un mayor número de dibujos de los que contenía aquél26.

Sin embargo, después de todos estos trámites y esfuerzos por adelantar en la edición de estos trabajos, los años transcurrieron y nada se pudo lograr al

23 Oficio de Lagasca [al ministro de Estado. Madrid, 1817-1819]. RJB, I,14,2,6.

24 Oficio de Antonio Gutiérrez a Lagasca. Madrid, 18 de octubre de 1819. RJB, I,29,3,1.

25 Oficio del marqués de Santa Cruz a Lagasca. Madrid, 26 de diciembre de 1819. RJB, $\mathrm{I}, 29,4,8$.

26 Oficios de Lagasca a la JPMCN y al marqués de Santa Cruz. Madrid, 28 de diciembre de 1819. RJB, I,57,6,8 y I,29,6,7. 
respecto. Las diversas ocupaciones de Lagasca y su posterior exilio le impidieron quizás tratar con mayor insistencia el tema ante los responsables de la política científica española una vez finalizado el Trienio Liberal. En estos años también se ocuparon de estos materiales Simón de Rojas Clemente, Antonio Sandalio de Arias y José Pavón, encargado por la Regencia en nombre del rey, de las colecciones botánicas del Nuevo Reino de Granada depositadas en una sala habilitada al efecto en el RJB, nombramiento del que fue relevado en 1827 y reclamadas las llaves que poseía de la sala de Mutis y demás departamentos del RJB27.

Del examen de los materiales llegados a Madrid, además de las observaciones geográficas, agrícolas, comerciales, físicas, médicas, astronómicas de Nueva Granada se sumaban las de índole naturalista, entre las que destacaba su muy adelantada, de cara a su publicación, Flora de Santa Fé. Contenía más de cuatro mil plantas, cuya historia ilustra con los usos médicos, económicos y con los más de seis mil dibujos, incluidos los duplicados en negro, «muy superiores a cuantos se han publicado de todas ellas, iluminados con sus propios colores y executados la vista y bajo su dirección por pintores hábiles». Además, entre los materiales llegados a Madrid, estaba el herbario correspondiente a la misma Flora con unos 20.000 ejemplares, numerosos frutos, semillas, maderas, bálsamos, resinas y demás productos vegetales, así como los manuscritos entre los que estaba la muy acabada «Historia natural, médica y comercial de las Quinas del nuevo Reyno de Granada». Según comenta Lagasca, al parecer en medio de convulsión política preindependentista que se produjo en el territorio neogranadino, un grupo de «facciosos» tuvo «contratada y a la venta de todo a un extranjero por el ínfimo precio de doscientos mil duros», pérdida que se hubiera producido si no lo hubieran impedido las armas de los generales Morillo y Enrile 28 .

De la fama de Mutis, al que Linneo consideró como el mayor botánico de cuantos habían pisado el suelo americano, se puede decir que alcanzó cotas insospechadas entre la comunidad científica nacional e internacional. Destacaron las favorables opiniones de botánicos insignes como Cavanilles y los ilustres viajeros Humboldt y Bonpland. Humboldt, por su parte, publicó varias láminas de plantas, realizadas en un estilo que a veces recuerda la iconografía mutisiana de la Flora de Bogotá.

27 Oficio de José Pavón a José Demetrio Rodríguez. Madrid, 19 de agosto de 1819. RJB, $\mathrm{I}, 40,5,14$.

28 Informe incompleto y sin fachar sobre José Celestino Mutis, de autor desconocido pero con anotaciones de Lagasca. RJB, I,15,5,12. 


\section{CRÉdito SOliCITADO POR LAGASCA A HuMBOLdT EN RELACIÓN A MutiS}

En la segunda carta de Lagasca a Humboldt, el primero solicitaba que $d i$ era a Mutis el crédito como autor intelectual de los dibujos representados en algunas obras de Humboldt, como Plantae aequinoctiales, por considerar que se habían copiado de la Flora de Bogotá de José Celestino Mutis. Lagasca insistía en que si no lo había hecho ya en la Biografía de Mutis que se supone publicaría Humboldt, debía este reconocimiento al sabio gaditano y a su patria, que tan generosamente se había portado con él en el momento de plantear su viaje americano.

La realidad es que Humboldt y Bonpland habían dedicado su obra Plantae aequinoctiales, publicada en París en 1805, a José Celestino Mutis como director de la Expedición Botánica del Reino de la Nueva Granada y astrónomo real en Santa Fé de Bogotá, «como una tímida prueba de admiración y reconocimiento». Aún así, en el prefacio de su obra, Humboldt insistió mucho —quizá demasiado - en la mayor extensión de su exploración botánica en comparación con las expediciones de Mutis, Ruiz y Pavón o Sessé, Mociño y Cervantes. Respecto a Mutis comentaba:

«M. Mutis a examiné, long-temps avant nous, les forêts de Turbaco, les belles rives de la Madeleine et les environs de Mariquita; mais ce grand botaniste, don't les bontés nous imposent une reconnoissance éternelle, n'a pas pu pénétrer par les Andes de Quindiu dans les provinces de Popayán et Pasto. C'est dans ces regions, sur les bords du Cauca et sur le haut plateau qui s'étend d'Almaguer jusqu'a la ville d'Ibarra, que nous avons recueilli des végétaux précieux» ${ }^{29}$.

Aclaraba también Humboldt que a las descripciones de las nuevas especies añadiría unos interesantes dibujos, con detalles de las partes esenciales de la fructificación - trabajo de los dibujantes Turpin y Poiteau, posteriormente grabado por Sellier - sin que hiciera la más leve referencia a que fueran copia de los dibujos de Mutis, cuya autoría reclamaba Lagasca en una de sus cartas. Sí aparecía un comentario expreso a dibujos de Mutis al hablar de las quinas, en la descripción de Cinchona condaminea, donde expresaba que Mutis había descubierto numerosas especies, «dont l'Institut et le Muséum possédent les magnifiques dessins remis par M. de Humboldt de la part de M. Mutis» ${ }^{30}$. Por el contario señalaba su prioridad en otros casos como en el del

29 Humboldt, A. et Bonpland, A. (1805), Plantae Aequinoctiales, Vol. I, Tome premier, Paris, Chez Levrault, Schoell et Comp., p. II.

30 Ibidem, p. 37. 
bejuco del guaco (Mikania guaco), descubierto por Mutis, pero representado por primera vez en Plantae aequinoctiales (tomo 2, pág. 85, plancha 105) ) $^{31}$. En cuanto a la posible prioridad del descubrimiento de algunas especies por los botánicos españoles, Humboldt se adelantaba diciendo:

«Nous possédons sans doute beaucoup de plantes qui se trouvent dans les herbiers de nos amis, MM. Mutis, Ruiz, Pavón, Cervantes, Mociño et Sessé: ayant herborisé dans des pays qui juissent d'un climat analogue, il est naturel que nous ayons rencontré les mêmes végétaux. Ce sera pour nous un devoir bien doux à remplir que d'indiquer ce que nous devons à ces botanistes célebres; mais ce ne sera notre faute si quelquefois, ignorant leurs travaux, nous donnons de nouveaux noms à des genres auxquels ils peuvent en avoir destiné d'autres long-temps avant nous» ${ }^{32}$.

31 Biographie Universelle..., (1843), p. 661.

32 Ibidem, p. V. 


\section{ANEXO \\ CARTAS DE LAGASCA A HUMBOLDT ${ }^{33}$}

Londres 30. de Abril de 1827

25. Camden Place, Camden town.

Señor Barón $\mathrm{D}^{\mathrm{n}}$. Alejandro de Humboldt.

Muy Señor mío, de mi mayor aprecio y respeto: no tengo inconveniente alguno en dar à V. Las noticias que desea à cerca de las cosas pertenecientes à la expedición botánica de Santa Fé de Bogotá que estuvo à cargo del inmortal Dn. José Celestino Mutis, y que fueron traídas à Madrid en 1817 por el teniente Coronel graduado $\mathrm{D}^{\mathrm{n}}$. Antonio de Van-Halen, ayudante del general $\mathrm{D}^{\mathrm{n}}$. Pablo Morillo, de cuya orden fueron traídas à Europa.

En el mismo Palacio del Rey, y por orden verbal de S.M. se me entregaron el día tres de octubre de dicho año, ciento y cinco cajones, de los cuales diez y ocho, que contenían minerales y antigüedades, y creo que también un paquete de dibujos de insectos, fueron conducidos inmediatamente al Gabinete de Historia natural de Madrid, y los ochenta y siete restantes se llevaron al Jardín botánico, juntamente con el inventario de lo que contenían todos, formado en Sta. Fé de Bogotá por $\mathrm{D}^{\mathrm{n}}$. Sinforoso Mutis, sobrino del difunto $\mathrm{D}^{\mathrm{n}}$. Jose Celestino, à quien encargó este trabajo y la colocación de todo el mismo general Morillo, que lo había indultado de la pena de muerte en atención à la buena memoria de su tío, según así me dijo el general $\mathrm{D}^{\mathrm{n}}$. Pasqual Henrile (sic).

Todos los cajones llegaron en el mejor estado, y sin haber recibido daño alguno en todo el viaje. Doce de ellos vinieron llenos de dibujos, cuyo numero total ascendió à seis mil novecientos sesenta y nueve, aunque en el inventario solo se mencionaban unos cinco mil doscientos. Los seis mil, poco mas ò menos, de dichos dibujos están ejecutados en papel de folio mayor de exquisita calidad; quinientos noventa en papel mas reducido son copias de estampas publicadas en diferentes obras; y como unos trescientos, en folio regular, representan únicamente la fructificación de varios géneros. De los primeros seis mil la mitad están en negro, y la otra mitad magníficamente iluminados; y habiendo para cada planta un dibujo en negro y otro iluminado, se deja ver que los seis mil solo representan unas tres mil especies diversas de plantas.

Hay una cantidad muy considerable de manuscritos, y se puede decir que los Diarios de los viajes de Mutis, escritos todos de su propia mano, forman una gran parte de la colección, y además me acuerdo en globo de los siguientes:

33 Academia de Ciencias de Berlín-Brandenburgo, Archivo de Alexander von Humboldt, Diario VII, b y c, 289V-300R. 
$1^{\circ}$. Quinología; ò sea, tratado de la Quina. Este manuscrito forma un gran tomo en folio, y esta precedido de un Prologo, escrito por $\mathrm{D}^{\mathrm{n}}$. Sinforoso Mutis, á quien parece encargó la publicación de esta obra el Gobierno de la Republica de Cundinamarca. Venían dos copias en limpio de este manuscrito, y de los dibujos correspondientes à el, que eran ciento veinte y dos, ò sea, sesenta y uno duplicados, mitad en negro y mitad iluminados, los cuales representan siete especies de quina, y diferentes variedades de las mismas, según el modo de ver del autor.

$2^{\circ}$. Varios informes sobre el cultivo, recolección, conservación y comercio de las quinas.

$3^{\circ}$. Diferentes traducciones de varias obras publicadas, como son el Tableau $d u$ Regne vegetal de Ventenat, del Genera Plantarum de Jussieu, y de la Geographie vegetale de Humboldt.

$4^{\text {o }}$. Un Diccionario botánico, es decir, de las palabras técnicas de la Botánica.

$5^{\circ}$. Varios legajos de caracteres genéricos naturales, copiados de diferentes obras publicadas después de la muerte de Linneo, como son las de Cavanilles a L'Heritier, Vahl, Ruiz y Pavón, Schreber, y otros. En mi concepto son materiales que recogía para formar un Genera Plantarum.

$6^{\circ}$. Otros muchos legajos de caracteres genéricos naturales escritos en lenguaje de Necker.

$7^{\circ}$. Algunos cuadernos de caracteres genéricos diferenciales, dispuestos según el sistema sexual Linneano; escritos en latín, como los de los núms.. $5^{\circ}$. Y $6^{\circ}$.

$8^{\circ}$. Como unas cuatrocientas descripciones de plantas, en borrador, escritas en latín.

$9^{\circ}$. Algunos informes sobre Minas.

$10^{\circ}$. Diferentes Legajos de minutas de oficios y representaciones.

$11^{\circ}$. Varios legajos de cartas de algunos sabios, de discípulos y amigos.

$12^{\circ}$. Varios papeles sobre gastos domésticos.

$13^{\circ}$. Varios cuadernos con observaciones astronómicas.

$14^{\mathrm{o}}$. Algunos manuscritos de su sobrino $\mathrm{D}^{\mathrm{n}}$. Sinforoso, y otros del malogrado $\mathrm{D}^{\mathrm{n}}$. Francisco José de Caldas.

$15^{\circ}$. Otros legajos, que contendrán noticias interesantes para la historia civil y política moderna del virreinato de Sta. Fe, y que supongo habrán sido ya remitidos à la Secretaría de Estado correspondiente.

El Herbario ocupaba unos sesenta cajones, de los quales solo llegué à abrir seis ò siete. Dos de éstos contenían muestras de quinas bastante repetidas; uno Gramíneas, Cyperoideas, y Juncaceas; otro compuestas, otro especies de géneros de diversas familias; y otro casi enteramente de plantas europeas.

Cuando se abrieron todos los cajones en el Palacio del Rey, para que S.M. viese lo que contenían, observé uno ò dos cajones llenos de esqueletos bien conservados de 
Melastomas y Rhexias, correspondientes sin duda à la magnífica colección de dibujos que venían de las numerosas especies de estos dos géneros.

En estos cajones ni un solo ejemplar vi denominado completamente: à lo más tenía alguno de ellos un papelito con un número ò con un nombre vulgar, y muy rara vez el nombre genérico: solo las plantas europeas estaban denominadas por los sujetos que se las enviaban. Los insectos habían causado algún estrago en la fructificación de varios esqueletos de las compuestas, los demás estaban muy bien conservados, y es de presumir que los restantes, que yo no tuve tiempo de ver se encontrarán en el mismo buen estado.

No me acuerdo cuántos sean los cajones con frutos y semillas que llegaron; yo solo registré uno, y observé que ni las simientes ni los frutos venían denominados.

Hay cuatro ò cinco cajones con muestras de maderas, que contendrán, en mi juicio, más de mil y quinientas muestras diferentes, todas numeradas, cuyo catálogo no se había encontrado.

Tampoco me acuerdo fijamente del número de cajones en que venían las raíces, cortezas, gomas y demás productos de la vegetación; pero me parece que no pasan de cuatro ò cinco.

Así pues, sabiendo de cierto que los dibujos ocupaban doce cajones, y estando casi cierto que las maderas ocupaban cuatro de los mismos; los manuscritos otros cuatro; los frutos y semillas tres; las raíces, cortezas, etc. cuatro; resulta que el herbario ocupaba sesenta cajones de los ochenta y siete que se me entregaron.

Comparando este sucinto resumen con la relación que insertó en las páginas 28 y 29 del segundo tomo de los Anales de ciencias naturales de Madrid el célebre Cavanilles, por noticias que le había dado $\mathrm{D}^{\mathrm{n}}$. Francisco Antonio Zea, discípulo de Mutis, se deja ver que faltan bastantes manuscritos, y los dibujos pertenecientes à la zoología de la Nueva Granada. Sujetos muy fidedignos me aseguraron haber leído en casa del mismo Mutis la obra manuscrita de éste sobre las Hormigas, y puedo asegurar à V. que habiendo registrado los manuscritos, que llegaron a Madrid, hoja por hoja, ni una sola línea he encontrado que hablase de este asunto.

También se echa de ver una notable diferencia en el número de dibujos, y mucho mayor aún en el de las descripciones que Zea hace subir à cuatro mil, y que yo creo muy verosímil fuesen al menos tantas cuantas son las diferentes especies de plantas que representan los dibujos.

Acuérdome haber visto entre los manuscritos de Mutis un papel escrito por su sobrino $\mathrm{D}^{\mathrm{n}}$. Sinforoso, en el cual se lamentaba de la pérdida de varios manuscritos, y esqueletos de plantas, y echa la culpa a un sujeto, (que no nombra) de quien dice hacía la mayor confianza su difunto tío. Lo cierto es que faltan hasta las descripciones de diferentes plantas que él remitió a Linneo, y fueron publicadas por el hijo de éste en su Supplementum.

Lo voluminoso de los diarios de Mutis, escritos enteramente de su propio puño; las observaciones varias que se ven en ellos apuntadas, muy conforme a la vasta extensión de conocimientos que poseía; y el número y exactitud de los dibujos, mani- 
fiestan claramente en mi concepto que acumulaba materiales para escribir muchos volúmenes sobre diversas materias, y habiendo disfrutado de una larga vida, y de medios suficientes para extender sus observaciones; es muy probable que los escribió con efecto, y que por los sucesos políticos que sobrevinieron a su muerte, han desaparecido muchos de ellos.

Esto mismo me parece que se infiere de la carta de V. escrita desde México al difunto Cavanilles, cuyo extracto se encuentra en el tomo sexto de los Anales de Ciencias naturales de Madrid.

Me parece no se disgustará $\mathrm{V}$. de leer un pequeño bosquejo de lo acaecido respecto de esta colección desde su llegada a Madrid. Apenas me restablezca lo extenderé con mucho gusto y se lo remitiré a V. Entretanto queda de V. como siempre su muy afecto Señor.

Q.B.S.M. de V. Mariano La Gasca

$\mathrm{S}^{\text {or }}$. Barón $\mathrm{D}^{\mathrm{n}}$. Alejandro de Humboldt.

Londres 3 de Mayo de 1827

25. Camden Place, Camden town.

Señor Barón $\mathrm{D}^{\mathrm{n}}$. Alejandro ${ }^{\text {de }}$ Humboldt

Muy Señor mío de mi mayor respeto y aprecio: cumpliendo la palabra que di a V. en mi anterior, digo: que era tan grande la opinión que yo había formado de los trabajos científicos de Mutis, por las varias relaciones que de ellos habían hecho diferentes sabios nacionales y extranjeros, que deseaba con la mayor ansia el momento feliz de verlos. Apenas supe el fallecimiento de Mutis principié a temer sufriesen la misma suerte que los de otros muchos ilustres españoles, que o desaparecieron para siempre, o se sepultaron en los archivos de las secretarías, o pasaron a manos extranjeras. Apenas podía consolarme de la pérdida de tan preciosos objetos, en cuya adquisición el Gobierno español había empleado, según tengo entendido, cerca de cuarenta millones de reales vellón, y un sabio tan distinguido como Mutis el tiempo más precioso de su larga vida. Yo supe después por el mismo general D. P. Enrile que mis continuos lamentos habían hecho la más viva impresión en su ánimo, y que salió decidido de Madrid a salvar cuanto pudiese de la expedición botánica de Mutis, como efectivamente lo hizo.

Llegados a Madrid los efectos referidos de dicha expedición, que venían rotulados al Ministerio de Estado, como pertenecientes al Real Jardín botánico y Gabinete de 
Historia natural, muy pronto nacieron otros temores. Al momento los reclamó como pertenencia de su departamento el Secretario de Estado de Gracia y Justicia de Indias, a pesar de hallarse vigente una Real Orden que en 1814 pude alcanzar, por la cual se disponía que en el caso de fallecimiento de los jefes encargados de semejantes expediciones, se depositase todo en el Jardín botánico de Madrid, para que allí se conservase, y sirviese a la instrucción pública. Desde luego descubrí en el paso dado por la Secretaría de Gracia y Justicia, una mano oculta, enemiga de la gloria de Mutis, que quería perseguirlo más allá del sepulcro.

Disputaron la pertenencia algunos meses los dos Secretarios de Estado, y sus contiendas fueron dirimidas por el Rey mismo, como dije en mi anterior. Durante estas contiendas, y temiendo venciese al fin el Secretario de Gracia y Justicia, que según se decía, gozaba entonces todo el favor del Rey; recurrí a S.M. pidiéndole la gracia de que fuese yo el encargado de la publicación de la Quinología de Mutis, que sabía por los Señores Enrile y Van-Halen, venía enteramente concluida y dispuesta para la prensa. Mi principal objeto en esta solicitud era salvar a todo trance esta obra de las manos de su enemigo, que según yo creía, la hubiese sepultado, o tal vez hecho quemar, como lo hizo con las quinas enviadas muchos años antes por el mismo Mutis.

Venció al fin el primer Secretario de Estado, y yo me encontré bien a pesar mío con el encargo de la publicación de la parte botánica, según verá $\mathrm{V}$. en la copia del oficio que se me pasó. Digo, bien a pesar mío, porque en efecto recibí en ello mi pesar. Reflexionando muchas veces sobre las causas del atraso de la Botánica en España, siempre hallé que la principal era la falta de buenos libros de poco coste; y así hacía ya algunos años que había determinado dedicarme exclusivamente a la publicación de la Flora española, y del Hortus matritensis, para las cuales había reunido muchísimos materiales, teniendo además en mi cabeza la ejecución de un Sistema generale vegetali y algunas otras. Había, además, empeñado solemnemente mi palabra para publicar la ceres española, trabajaba entonces en las adiciones de la nueva edición de la Agricultura de Herrera, y tenía a mi cargo la dirección y enseñanza pública del Jardín, y la inspección general de los plantíos del canal de Manzanares. Así pues esta comisión sobre perjudicar a mi misma gloria literaria, era un impedimento para los progresos generales de la ciencia en mi verdadera patria. Pero ya insinué que no pude resistir este mal.

Meses pasaron sin que se me diese auxilio alguno y sufrí no pocos sinsabores para lograr el que al fin conseguí en Febrero de 1818 para componer el Salón, en que debía colocarse la nueva cajonería destinada a contener el herbario, dibujos y demás, perteneciente a dicha expedición.

Todo venía desordenado; pero con particularidad los manuscritos, a excepción de la Quinología y el Diccionario botánico. Fueron necesarios algunos meses de trabajo continuado para darles algún arreglo, y poder formar un inventario algo ordenado. De los dibujos solo unos quinientos venían denominados, los demás por lo general sin nombre, y cuando más traían solo el genérico; pero todos estaban numerados en el dorso; mas la llave de dichos números no vino. Yo denominé un gran número de 
ellos, singularmente de los de las Compuestas y Gramíneas; y casi todos los 530 del Apéndice, que dispuestos por familias naturales, se colocaron separados de los de la Flora de Santa Fé. Los de ésta los coloqué, según el Sistema Linneano, anunciando al Gobierno que su último arreglo sería por familias naturales.

Sabedor de que se habían perdido muchísimos objetos de otras expediciones semejantes, y deseando evitar sucediese otro tanto con los de la de Mutis, antes de entregarme de ellos, pedí al Gobierno, que el Capitán Don Antonio Van-Halen, me los entregase con toda formalidad bajo rigurosísimo inventario, y que asistiese a este acto otra persona inteligente. El Gobierno así lo mandó, y nombró al efecto al Dr. $\mathrm{D}^{\mathrm{n}}$. Simón de Rojas Clemente, Bibliotecario del Real Jardín botánico. El señor VanHalen, aunque no es naturalista, es un oficial de mérito distinguido, que se había educado en una de las escuelas de la Marina Real española, de donde pasó al Ejército de tierra durante la guerra contra Napoleón; apreciaba mucho lo que con tanto cuido había traído, y tuvo la imponderable paciencia de asistir puntualísimamente a toda la entrega, auxiliándome no poco en la coordinación de los manuscritos.

Los inventarios están hechos con la mayor escrupulosidad; todas las hojas de los manuscritos están rubricadas por los tres; de manera que ni un solo dibujo, ni una cuartilla de manuscrito puede faltar sin que sea por culpa del encargado de ello. Otro tanto hice con la parte de herbario que yo pude colocar. Si algo faltare no será por falta de previsión al formar los inventarios, será por descuido o por inmoralidad del encargado, como sucede actualmente con los objetos correspondientes a las expediciones del Perú y Chile, y de la Nueva España.

Los estantes están pintados al ólio, tienen puertas dobles; además están forrados en hojalata por la espalda y por todos los costados para que los ratones no puedan jamás horadarlos. Los manuscritos y dibujos están además dentro de unas cajas bien cerradas que se embuten en nichos practicados al efecto en dichos estantes. El papel para el herbario es de folio mayor y de excelente calidad, hecho al efecto, y a toda mi satisfacción. La pieza o salón, es enjuto, y el más fresco de todos los edificios del jardín en el verano, en dicho salón hay una mesa suficientemente ancha y del largo del mismo salón, sobre la cual pueden compararse a la vez más de doscientos esqueletos de plantas.

Hecho el inventario de los dibujos, y casi para concluirse ya el de los manuscritos hice presente al Gobierno mis ocupaciones, le pedí un profesor que me auxiliase, proponiendo à $\mathrm{D}^{\mathrm{n}}$. Simón de Rojas Clemente y los libros necesarios para la publicación, y los antecedentes indispensables para formar la historia de la expedición. Se nombró a Clemente como yo pedía; pero sobre los libros y demás aún no se me ha contestado.

Ignoro si después de mi salida de Madrid el 4 de abril de 1823 habrá adelantado alguna cosa en los trabajos de esta expedición mi difunto amigo $\mathrm{D}^{\mathrm{n}}$. Simón de Roxas Clemente. Si algo ha hecho, seguramente será muy poco, ya porque este encargo lo miraba él como un estorbo que le impedía perfeccionar sus propias obras; ya por el estado valetudinario de su salud desde 1819, y ya porque desde la entrada del Exto. de Luis 18 en Madrid hasta el Septiembre de 1825 estuvo separado de su destino, y 
desterrado de la Corte por haber sido diputado en 1820 y 21. El conjunto de estas circunstancias, y el dolor que le causaría, como amigo que era de la libertad, el ver à su Patria sumergida en los horrores de la esclavitud, me persuaden tristemente que poco habrá adelantado. Quiera Dios que ahora haya pasado à manos más puras que las del malvado Pavón.

Cierro esta carta, asegurando à $\mathrm{V}$. que estoy firmemente persuadido que varios de los dibujos de las plantas publicadas por V. en sus obras tituladas Plantae aequinoctiales y Monographia Melastomae et Rhexiae son copias de los de la Flora de Bogotá, aunque por lo general más o menos recortados para acomodarlos al tamaño de la obra. Durante la vida de Mutis pudiera haber habido algún inconveniente en publicarlo así; pero ya desaparecieron semejantes motivos con su muerte; y no dudo, que si el hecho es igual yo lo concibo, V. lo publicará así, si es que ya no lo ha hecho en la Biografía de este sabio, que no he visto. En ello va una parte de la gloria literaria de Mutis, y de su patria y la mía, cuyo gobierno facilitó à V. con generosidad poco común, los medios de aumentar la suya propia, que no creo se disminuya por semejante declaración.

Concluyo asegurándole à $\mathrm{V}$. que no tengo inconveniente alguno en que se publique el contenido de esta carta y de la anterior, pues que el Gobierno español lejos de querer guardar secreto en esta parte, deseaba que la Europa supiese lo que contenían los 105 cajones llegados à Europa.

Suplico à V. Tenga la bondad de dar la correspondiente dirección à la adjunta carta que remito para el célebre profesor Mr . Link, y aceptar un exemplar de mi Memoria sobre las Aparasoladas, aunque creo la remití à V. en 1825 con mi discípulo $\mathrm{D}^{\mathrm{n}}$. Tomás de Betancourt.

Deseo à V. un felicísimo viaje, y muchos años de vida para concluir sus nuevas obras. Vea $\mathrm{V}$. en qué pueda serle útil su afmo.

\author{
Q.B.S.M. \\ Mariano La Gasca
}

\title{
P.S. Londres 25 de Julio de 1831.
}

He tenido esta carta conservada, que no entregué à V. por haber llegado a su casa à poco de haber salido V. para el continente. Hoy mismo escribo al Sr. Link, y le incluyo los cuadernos que debía haber entregado à $\mathrm{V}$. para él. Me dijo Vd. que iba à publicar una Geografía vegetal bajo un plan distinto que el anterior. La ha publicado Vd.? Tengo algunas esperanzas de hacer algo en la Flora Española.

$\mathrm{S}^{\text {or }}$. Barón $\mathrm{D}^{\mathrm{n}}$. Alejandro de Humboldt. 